\title{
MULHERES E A PINTURA PARANAENSE: RELAÇÃO ENTRE ARTE E GÊNERO (FIM DO SÉCULO XIX E COMEÇO DO SÉCULO XX) ${ }^{1}$
}

\author{
Women and paranaense painting: the relationship \\ between art and gender (end of the nineteenth \\ century and early twentieth century)
}

\section{Claudia Priori*}

\begin{abstract}
RESUMO
Este artigo aborda a presença e atuação de mulheres no campo da arte paranaense, no fim do século XIX e começo do século XX, analisando os espaços ocupados por elas nesse cenário artístico, suas trajetórias, expressões e ainda, como essas artistas eram vistas e representadas pela sociedade. Para isso, realizamos pesquisas na produção bibliográfica que trata da temática, jornais da época, bem como levantamento de dados junto aos acervos de museus. Nossa abordagem parte da perspetiva dos estudos de gênero, articulada com os estudos da Arte, pois essa temática é ainda carente de atenção por parte da historiografia, motivos que nos estimulam a problematizar os lugares das mulheres nas artes, especialmente na pintura, uma vez que as áreas da educação, da arte e da cultura eram restritas e pouco desenvolvidas na recémemancipada província. Além disso, os mundos das artes e da ciência eram poucos ocupados por mulheres, devido às imposições sociais, papéis e lugares atribuídos ao gênero feminino. Diante disso, buscamos analisar a relação entre arte e gênero, percebendo as implicações e dificuldades para a inserção feminina no campo artístico.
\end{abstract}

Palavras chave: Mulheres; História da arte; Gênero.

1 Este artigo é resultante de uma pesquisa em andamento com apoio financeiro do Conselho Nacional de Desenvolvimento Científico e Tecnológico (CNPq), Chamada Universal Edital n. 14/2014.

* Doutora pela UFPR e Professora Adjunta no Colegiado de História - Universidade Estadual do Paraná - Campus de Campo Mourão 


\begin{abstract}
This article discusses the presence and women acting in the field of art paranaense in the late nineteenth century and early twentieth century, analyzing the spaces occupied by them in this art scene, their trajectories, expressions and also how these artists were seen and represented by society. For this, we conduct research in bibliographic production that deals with the theme, including magazines and newspapers of the time, as well as data collection by the collection of museums. Our part of the prospective approach of gender studies, in conjunction with the Art area, as this issue is still in need of attention from the history, reasons that encourage us to question the places of women in art, especially in painting, since the areas of education, art and culture were restricted and undeveloped in the newly emancipated province. Moreover, the world of arts and science was little occupied by women due to social constraints, roles and places to be occupied by females. Therefore, we analyze the relationship between art and gender, realizing the implications and difficulties in integrating women in the artistic field.
\end{abstract}

Keywords: Women; Art History; Gender.

\title{
A inserção das mulheres nas artes $e$ a profissionalização
}

A utilização do gênero ${ }^{2}$ enquanto categoria de análise histórica permite decodificar e entender o sentido, o significado das complexas relações sociais de gênero, e ainda abre espaço para encontrar as mulheres nas suas diversas faces da feminilidade e os homens nas suas várias faces da masculinidade. $\mathrm{O}$ uso do gênero enquanto categoria analítica possibilita o questionamento e a fuga do dualismo oposicionista e essencialista de que o masculino é forte/viril e o feminino é fraco/frágil, uma hierarquização de gênero que forjou relações desiguais de poder ao criarem estereótipos femininos e masculinos baseados em princípios de submissão e dominação.

2 SCOTT, Joan. Gênero: uma categoria útil de análise histórica. Educação e Realidade. Porto Alegre: vol.16, n. 2, 1990. 
Nesse prisma, faz-se necessário superar o aspecto demarcador e descritivo do gênero, e tratá-lo teoricamente, de forma relacional, compreendendo as complexas relações interpessoais e sociais em situações e contextos específicos, e principalmente, em quais espaços, lugares e configurações o gênero se coloca, se constrói e legitima relações de poder, ao delimitar espaços e posições que podem ou não ser ocupados na sociedade.

As mulheres sempre estiveram presentes nas artes, mas na grande maioria das vezes, apenas como inspiração, musas, ícones e modelos. Historicamente, pouquíssimas foram as mulheres que se destacaram como protagonistas, criadoras, artistas. Esse espaço criativo não era permitido a elas.

Assim, partimos das contribuições da abordagem da história cultural, da história das mulheres e dos estudos de gênero, articulados com os estudos da arte, para analisar a inserção feminina no cenário artístico paranaense, especificamente na pintura, bem como a relação entre arte e gênero no fim do século XIX e começo do século XX.

A historiadora Michelle Perrot aponta as dificuldades que as mulheres enfrentaram no século XIX para se inserirem no âmbito das artes,

Escrever foi difícil. Pintar, esculpir, compor música, criar arte foi ainda mais difícil. Isso por questões de princípio: a imagem e a música são formas de criação do mundo. Principalmente a música, linguagem dos deuses. As mulheres eram impróprias para isso. Como poderiam participar dessa colocação em forma, dessa orquestração do universo? As mulheres podem apenas copiar, traduzir, interpretar. Ser cantora lírica, por exemplo ${ }^{3}$.

As mulheres eram consideradas inaptas para o mundo das artes, da criação e da composição, produzir e criar eram considerados algo impróprio para o gênero feminino. A elas cabiam apenas a cópia, a tradução, a interpretação; cabia apenas ser a musa, objeto de 
inspiração para as artes feita pelos homens. Para as mulheres, a sociedade impunha a esfera privada e profissões como o magistério que remetiam à educação e cuidado das crianças, similar ao papel de mãe e educadora.

Encontramos no Brasil, nos fins do século XIX e começo do século XX, uma presença muito restrita de mulheres no mundo das artes, entretanto, algumas artistas começaram a ser reconhecidas profissionalmente, dentre elas Maria Martins, que na área da escultura chegou a ter destaque internacional e na pintura temos as modernistas Anita Malfatti e Tarsila do Amaral, certamente as mais conhecidas nacionalmente.

Mas antes dessas, ainda no século XIX, destaca-se no eixo Rio-São Paulo, a presença de pintoras como Abigail Andrade, Georgina de Albuquerque, Berthe Worms, e escultoras como Julieta de França e Nicolina de Assis Pinto do Couto, entre várias outras ${ }^{4}$.

Tivemos ainda em nível internacional algumas artistas que no decorrer do século XX se destacaram como, por exemplo, a pintora Frida Kahlo, e escultoras como Louise Bourgeois, Celeida Tostes, Niki de Saint Phalle, Judy Chicago e Ana Mendieta. Todavia, a presença delas é numericamente menor no mundo das artes se comparado à presença masculina.

Segundo Flavia Leme de Almeida,

[...] na história da arte, ainda temos um vasto campo para fomentar investigações acerca dessas mulheres que se tornaram artistas e suas respectivas obras. A maioria das nossas fontes de pesquisa sobre arte feminina são advindas de autores, europeus e norte-americanos que, obviamente, falam sobre artistas dessas localidades. Consequentemente, temos poucos registros sobre a produção de artistas mulheres contemporâneas que

4 SIMIONI, Ana Paula Cavalcanti. Profissão Artista: Pintoras e Escultoras Acadêmicas brasileiras. São Paulo: Fapesp, 2008. 
abordem a temática do feminino na América Central e do $\mathrm{Sul}^{5}$.

Pesquisar e ressaltar a vida e obras das artistas mulheres, segundo Almeida - também artista e escultora - é uma forma de evidenciar "que a mulher pode ser reconhecida integralmente, não apenas em âmbito social, mas também intelectual, artístico ou, até mesmo, ritualístico"6.

Quando abordamos o contexto específico do Paraná, percebemos que a realidade de inserção das mulheres nas artes e na profissão de artista não foi muito diferente do que acontecia nacional e internacionalmente. É preciso considerar que estamos nos referindo a um período em que a província ${ }^{7}$ começa a se projetar no cenário nacional e a capital, cidade de Curitiba, passa a se destacar na vida cultural e artística, no entanto, a condição das mulheres e a presença nos espaços artísticos eram quase nulas. Poucas foram as que conseguiram se inserir e se destacar no mundo das artes no fim do século XIX e início do século XX.

Nossa hipótese é que a pouca presença delas no âmbito artístico paranaense, não deve ser compreendida por uma ausência de mulheres talentos, mas por uma exclusão feminina nas carreiras de formação artística. Somente a partir de $1879^{8}$ foi permitido a elas o ingresso nos cursos superiores e a profissionalização, porém, a legislação nem sempre foi seguida de imediato, pois a Escola Nacional de Belas Artes (ENBA) - antiga Academia Imperial de Belas Artes - do Rio de Janeiro, só passou a aceitar matrículas de

5 ALMEIDA, Flavia Leme de. Mulheres recipientes: recortes poéticos do universo feminino nas artes visuais. São Paulo: Cultura Acadêmica, 2010, p. 18.

6 Idem, Ibidem, 2010, p. 20.

7 No período do Império, as unidades federativas eram chamadas de províncias. A província do Paraná se emancipou da capitania de São Paulo, em 1853. Com o advento da República em 1889, as antigas províncias recebem a denominação de estados.

8 Apenas em 19 de abril de 1879, D. Pedro II faz aprovar uma lei autorizando a presença feminina nos cursos superiores. A iniciativa do Imperador teria se dado devido ao episódio ocorrido com Augusta Generosa Estrela, que ao se diplomar em Medicina, em 1876, em New York, com uma bolsa de estudos concedida pelo próprio Imperador, foi impedida de exercer a profissão ao retornar ao Brasil. Conforme BLAY, Eva Alterman e CONCEIÇÃO, Rosana R. da. A mulher como tema nas disciplinas da USP. Cadernos de Pesquisa, n 76, fev., p. 50-56, 1991. 
mulheres a partir de 1893, portanto, já no período republicano. Isso demonstra como a legislação de 1879 foi tardiamente atendida, dificultando a profissionalização artística de mulheres.

Em relação ao caso francês, Perrot salienta que:

Uma verdadeira aprendizagem lhes era negada. Sob o pretexto de que o nu não devia ser exibido às moças, o acesso à Escola de Belas Artes lhes era vedado, a qual só lhes foi aberta, em Paris, a partir de 1900 , e sob as vaias dos estudantes. Antes dessa data, as jovens deviam se conformar com as escolas e academias particulares, sendo que, em Paris, a mais célebre foi a academia Jullian? .

A rara presença de mulheres na profissão de artista revela mais uma vez as questões ligadas aos papéis de gênero impostos socialmente, lhes atribuindo a função de esposa, procriadora e mãe dedicada. Os discursos predominantes alegavam que aquelas que rompessem com os parâmetros femininos estariam desequilibrando a "ordem natural" da sociedade, desafiando seu destino e papel de esposa e mãe. Fica evidente assim que "o mundo artístico não estava imune às pressões do gênero, ao contrário, era um campo em que as desigualdades, as posições, as diferenças se afirmavam e se reinventavam" ", como salienta Simioni. Desse modo, concordando com a autora, nossa perspetiva é de que a ausência ou pouca presença das mulheres no mundo das artes - especificamente no Paraná - pode ser entendida por meio da problemática de gênero, ou seja, resultado das desigualdades sociais de gênero a que as mulheres foram submetidas pelo contexto sociocultural, e não a uma falta de mulheres talentos, gênias, pois inteligência, racionalidade, imaginação, criatividade e inspiração artística as mulheres sempre tiveram, e técnica, conhecimento, saberes, experiência e criação elas sempre produziram.

9 PERROT, Michelle. Op. Cit, 2008, p.101.

10 SIMIONI, Ana Paula Cavalcanti. Op. Cit., 2008, p.72. 
As que conseguiram se inserir no mundo das artes - quando recebiam essa "permissão social" - enfrentaram muitas dificuldades, pois críticos, historiadores, curadores e museólogos tachavam a arte produzida pelas mulheres como amadorismo, uma arte feita para ocupar o tempo ocioso, um passatempo, forma de distração e entretenimento, e que exposto ao público servia apenas para ilustração, objeto decorativo, algo muito distante e incomparável com o profissionalismo masculino. Além disso, a arte feita por elas era muitas vezes chamada de "arte feminina" - considerada em alguns momentos como "arte menor" ou "subarte" - como se isso fosse algo inferior, isto é, como se a arte produzida por mulheres não tivesse a mesma qualidade que aquela feita pelos artistas homens. A arte produzida por mulheres era vista como "marginal", amadora, mera distração.

É importante mencionar que esse processo de marginalidade da história, do processo criativo, dos espaços públicos, lugares e posições sociais a que as mulheres foram submetidas socialmente, inclusive a profissão de artista, foi delimitada por códigos de uma sociedade patriarcal que renegava às mulheres o exercício da cultura, da criação, da produção e composição do mundo.

A arte produzida pelas mulheres no recorte temporal estudado, principalmente no que tange à pintura, geralmente representava a vida familiar, retratos e autorretratos, os espaços privados, as relações de gênero, as naturezas-mortas, e mais raramente retratavam animais, nus, cenas bíblicas e históricas. $\mathrm{Na}$ literatura, seus temas giravam em torno de poesias, assuntos familiares, sentimentos, maternidade. E essa produção artística das mulheres era vista como "arte feminina", amadora e pouco profissional.

Nesse sentido, Simioni assinala que:

Tal visão acabava por fortalecer a noção de que as obras feitas por artistas do sexo feminino eram pouco profissionais e incapazes de ser ombreadas com as masculinas. Em outras palavras, o fantasma do amadorismo, com tais discursos, tornava-se uma evidência. Os críticos procuravam o que acreditavam ser 
a expressão de uma feminilidade natural; fazendo isso, criavam a diferença, de modo a excluir as artistas da possibilidade de serem algo, que não, simplesmente diletantes ou amadoras ${ }^{11}$.

A profissão artista parecia não ser feita para as mulheres se expressarem livremente, pois, além de suas expressões artísticas não serem consideradas no mesmo patamar de qualidade dos artistas homens, ainda se cobravam delas que representassem em suas obras questões atribuídas ao "feminino": a domesticidade, os retratos familiares, a maternidade, a infância, a beleza, as naturezas-mortas, delimitando um espaço e temas "adequados" para as mulheres criarem. No entanto, essa criação artística não era aceita para se expor no espaço público, mas simplesmente para decorar a casa, presentear a família, recepcionar as pessoas amigas.

E quando as mulheres fugiam das temáticas ditas femininas, e ousavam representar outros temas, escrever e discutir sobre política, pintar cenas históricas, dançar, representar, compor e cantar, quando se expressavam com liberdade temática, poética e crítica eram rechaçadas pelo âmbito artístico masculino ou não eram reconhecidas socialmente, como aconteceu com muitas delas, ficando invisíveis no mundo das artes e na história da arte.

Historicamente, parece ser coerente que as artistas representassem, fizessem pinturas e escrevessem acerca de suas experiências e vivências no âmbito doméstico e familiar, já que na grande maioria das vezes, era a esses espaços que elas estiveram restritas por muito tempo. Os temas e cenários retratados pelas mulheres artistas não parecem ser motivos para causar espanto social, pois se a elas era reservado o "mundo feminino", e exigido atributos como a sensibilidade, a delicadeza e a emoção, é compreensível que muitas delas retratassem esse contexto sociocultural a que estavam inseridas, que revelassem um pouco desse mundo ao qual sua vida estava limitada. 


\section{Os lugares permitidos...}

Problematizar os espaços e lugares que as mulheres ocupavam, ou melhor, podiam ocupar na recém-província e na capital paranaense, de fins do século XIX e começo do século XX, é fundamental para termos acesso as suas produções e expressões artísticas. Nessa ótica, cabe questionar: teriam enfrentado dificuldades para expor sua arte? E, ainda, que diferença faz, as mulheres na arte? ${ }^{12}$. Essas questões são importantes para refletirmos acerca da presença e atuação das mulheres no campo da arte, especialmente da pintura no cenário curitibano.

As representações do feminino, desde os primórdios da história paranaense, estavam pautadas em um comportamento doméstico, recatado e agrário, onde o ensino e a educação feminina ficavam em segundo plano. As áreas da arte, cultura e educação eram restritas e pouco desenvolvidas na recém-emancipada província do Paraná, no fim do século XIX, como apontam as historiadoras Trindade e Andreazza ${ }^{13}$.

A partir de 1870, no campo da educação, Curitiba recebeu maior incentivo aos cursos de ensino secundário e particular - isso também ocorreu em cidades como Paranaguá, Morretes, Castro e Ponta Grossa - estabelecimentos que acolhiam quase que majoritariamente meninos e jovens da elite que se preparavam para as academias superiores.

Trindade e Andreazza afirmam que, para as meninas a situação era outra:

Para o sexo feminino, foram criados os colégios de Mme. Mariette, Mme.Taulois ou Mrs Brand que, disputando a clientela com o Nossa Senhora da Glória ou o Externato Santa Tereza, já prenunciavam o gosto cosmopolita que

12 Aqui faço alusão ao livro de JUSTINO, Maria José. Mulheres na Arte. Que diferença isso faz? $1^{\text {a }}$. ed. Curitiba: Museu Oscar Niemeyer, 2013.

13 TRINDADE, Etelvina M. de Castro; ANDREAZZA, Maria Luiza. Cultura $e$ Educação no Paraná. Coleção História do Paraná. Curitiba: SEED, 2001. 
iria predominar na educação das senhoras paranaenses na virada do século. Nesse momento, mais precisamente em 1896, chegava a Curitiba o primeiro bispo da Diocese, D. José de Camargo Barros que logo incentivou a vinda de padres e freiras católicos de diversas nacionalidades a fim de atenderem a população local e também as colônias de imigrantes. Para a educação das jeune filles curitibanas chegaram, ao fim do século, as congregações de religiosas francesas dos Santos Anjos e de São José de Chambéry ${ }^{14}$.

Desde a segunda metade do século XIX, algumas mulheres, principalmente as da elite tinham acesso ao ensino e recebiam a formação do magistério, estavam em contato com a literatura, a escrita, as correspondências e a imprensa, fatores esses que possibilitaram a entrada delas no mundo das artes, especialmente escrevendo e publicando poesias e literatura, cursando pintura, estudando música, porém, pouquíssimas são as que conseguiram destaque nesse universo ainda tão masculino. Quais seriam os motivos para essas dificuldades? Por que as produções de muitas artistas não chegaram ao público, às exposições, ao reconhecimento?

Teria razão a escritora e poetisa Adélia Maria Woellner? Ao afirmar que,

[...] sendo o paranaense tido como "autofágico", conservador, reservado, a mulher teria, como consequência, maior dificuldade para manifestar, com maior liberdade e autenticidade, seus sentimentos e emoções, percepções e opiniões ${ }^{15}$.

As dificuldades encontradas para a manifestação da escrita feminina, salientadas por Woellner, também se estende à história da

14 Idem, Ibidem, 2001, p. 62.

15 WOELLNER, Adélia Maria. Narrativas da Memória: o Discurso Feminino - A voz da mulher na literatura. Revista de Literatura, História e Memória, Vol. 3, nº 3, 2007, p. 14. 
arte, devido ao pouco espaço permitido às mulheres, em virtude da ênfase à imagem "do paranaense" como 'autofágico', conservador e reservado", ou seja, que se bastava a si próprio, defensor do status $q u o$, dos papéis de gênero impostos e aceitos socialmente. Com base nesses discursos de autofagia, conservadorismo, manutenção da ordem social e moral, as restrições impostas às mulheres agravavam os níveis de dificuldades enfrentados pelas artistas, pois se tornavam alvo de descrédito, uma vez que estariam desequilibrando a "ordem natural" da sociedade ao ocuparem espaços consagrados ao masculino. Com isso, retirava-se o protagonismo social das artistas, deixando-as nas sombras, dificultando a inserção social e o reconhecimento de seus trabalhos e produção artística, o que revela as desigualdades das relações sociais de gênero e os lugares permitidos a cada um no contexto estudado.

A historiografia nos mostra que Curitiba, a capital paranaense, no início do século $\mathrm{XX}$, período da primeira república, estava em busca de uma "identidade" e não foram poucas transformações socioculturais, políticas e econômicas pela quais passou $^{16}$, e as artes, de modo geral, foram utilizadas como meio de propagação desses ideais de uma "identidade" paranaense. A capital caminhava ao encalço do progresso, da civilidade, do desenvolvimento urbano e industrial, e se direcionava ao encontro da arte e da cultura em busca de aspectos que reforçassem o projeto de

16 CARNEIRO, Cíntia Braga. O Museu Paranaense e Romário Martins: a busca de uma identidade para o Paraná. Curitiba: SAMP, 2013; TRINDADE, Etelvina Maria de Castro. Clotildes ou Marias: mulheres de Curitiba na Primeira República. Curitiba: Fundação Cultural, 1996; SEGA, Rafael Augustos. A Capital Belle Époque: a reestruturação do quadro urbano de Curitiba durante a gestão do prefeito Cândido de Abreu (1913-1916). Curitiba: Ed. Aos Quatro Ventos, 2001; RIBEIRO, Luiz Carlos. Memória, trabalho e resistência em Curitiba (1890-1920). São Paulo, Dissertação de Mestrado, 1985; PEREIRA, Magnus R.M. Semeando Iras ao Progresso. Curitiba: Editora da UFPR, 1996; LORENZETTI, Fernanda. O futuro paranaense em seu meio natural: a escrita de Domingos Nascimento e a produção de identidade ao Paraná no início do século XX. Revista Tempo, Espaço e Linguagem, vol.1, n. 1, Jan.Jul./2010; MARTINS, Romário. História do Paraná. Curitiba: Travessa dos Editores, 1995; PRIORI, Angelo [et al]. História do Paraná: séculos XIX e XX. Maringá: Eduem, 2012; DICIONÁRIO HISTÓRICO-BIOGRÁFICO DO ESTADO DO PARANÁ. Curitiba: Chain/Banco do Estado do Paraná, 1991; TRINDADE, Etelvina Maria de Castro e MARTINS, Ana Paula Vosne (orgs.). Mulheres na história: Paraná - século 19 e 20. Curitiba: UFPR, 1997; KAMINSKI, Rosane. O belo, efêmero, o gosto brejeiro: imagens da vida fugidia nas revistas curitibanas (1900-1920). Disponível em: http://revistascuritibanas.ufpr.br/artigos.php Acesso em: $16 / 04 / 2015$. 
modernização e industrialização, o que de fato atraía muitas famílias de migrantes e imigrantes.

Nessa época já era visível o crescimento de espaços públicos voltados ao lazer, como cafés e casas de espetáculos, salões de danças, praças e parques, teatros e cinemas, clubes, associações e grêmios. Constantemente se via nas ruas a presença de mulheres que transitavam desacompanhadas, entrando nas lojas e armarinhos. Além disso, houve um crescimento progressivo do trabalho feminino nas fábricas, nos escritórios empresariais, nos balcões comerciais, nas casas da elite curitibana, em trabalhos manuais como floristas, chapeleiras, costureiras, modistas, entre outras. Não podemos nos esquecer das parteiras, e de tantas outras mulheres que se inseriram no ensino - como professoras ou diretoras de escolas - como formas de obter sustento e recursos econômicos.

Nas primeiras décadas do século XX, algumas mulheres adentraram as profissões liberais, como médicas, odontólogas, advogadas e farmacêuticas ${ }^{17}$. Temos que destacar, sobretudo, as mulheres artistas, protagonistas presentes nesse cenário: pintoras, literatas, musicistas, poetisas, atrizes de teatro, escultoras, que embora encontrassem dificuldades para alcançar espaço na sociedade - assim como nas demais profissões - elas existiam e cada vez se proliferavam mais.

Analisando a produção bibliográfica que trata da temática jornais ${ }^{18}$ da época, livros e catálogos de exposição do acervo do Museu Paranaense ${ }^{19}$ e Museu Alfredo Andersen ${ }^{20}$ disponíveis online -

17 TRINDADE, Etelvina Maria de Castro. Op. Cit.,1996.

18 Jornal Dezenove de Dezembro - 1884 - Edição XXXI; 1885 - Jan. à Jun. - XXXII e Jul. à Dez. - XXXII; 1886 - Jan. à Jun. - XXXIII e Jul. à Dez. - XXXIII; 1887 - XXXIV - Acervo da Biblioteca Romário Martins - Museu Paranaense.

19 Livros disponíveis online na Biblioteca Romário Martins (Museu Paranaense) Exposição Arte no Paraná: fases itinerante e infra-estrutura (11 de maio a 08 de julho de 1990). Curitiba: Biblioteca do Museu Paranaense, 1991; CARNEIRO, Newton. As artes e o artesanato no Paraná. Curitiba, 1955; MUSEU PARANAENSE. A Gênese do Museu Paranaense (1874-1882). Auspiciosa experiência de aclimação cultural na Província. Arquivos do Museu Paranaense, Nova Série- História - N.01, 1976; BADEP, Panorama da Arte no Paraná. I - Dos precursores à escola Andersen. Curitiba, 1975; BANESTADO, Pintores e escultores II. As Escolas de Mariano de Lima e de Alfredo Andersen: ponto de partida. Curitiba, s/d.; CARNEIRO JUNIOR, Renato Augusto (coord.). Personagens da História do Paraná: acervo do Museu Paranaense. Curitiba: SAMP, Museu Paranaense, 2014.

20 Museu Alfredo Andersen. Disponível em: http://www.maa.pr.gov.br/ 
buscamos mapear a presença e atuação das mulheres na arte paranaense, especialmente na pintura. Desde meados do século XIX, as mulheres pintoras despontavam no campo do ensino, como é o exemplo de Jéssica e Willie James - mãe e filha - ambas naturais dos Estados Unidos, precursoras do ensino das artes no Paraná. Juntas fundaram em Paranaguá uma escola de desenho e pintura - Colégio Particular Feminino James - onde as moças recebiam aulas de doutrina cristã, leitura, caligrafia, aritmética, línguas portuguesa, francesa e inglesa, geografia, história, música, desenho, dança, pintura e bordados.

Em seguida, chegou a família Taulois que também fundou um colégio para meninas, em Paranaguá, que naquele momento era um importante centro comercial e político da província do Paraná. A cidade portuária era local de chegada de estrangeiros, viajantes e artistas que aportavam naquelas terras, em que havia muitas famílias abastadas e que investiam no sistema educacional pensando na formação de seus filhos e filhas ${ }^{21}$.

À Jéssica James foi atribuída a autoria do retrato do Comendador Joaquim Américo Guimarães ${ }^{22}$, que segundo o escritor David Carneiro,

É verdade que a Da. Jéssica deixou um retrato a óleo, o único que dela se conhece. É o retrato do Comendador Joaquim Américo Guimarães. A autenticação, além de haver sido feita pelo Sr. José Gonçalves Lôbo, tem cunho mais precioso: Alfredo Andersen que o retocou, colocou num jornal que o retratado traz na mão, a declaração seguinte: Pintado em 1865 por Willie cidadão do Rio de Janeiro.

21 CORRÊA, Amélia Siegel. Alfredo Andersen: um pai norueguês para a pintura paranaense. 19\&20, Rio de Janeiro, v. IV, n.2, abr. 2009. Disponível em: <http://www.dezenovevinte.net/artistas/andersen_asc.htm

22 Acervo Online do Museu Paranaense. Coleção David Carneiro. Retrato Joaquim Américo Guimarães (Comendador), Óleo sobre tela, 1865, $105 \times 73 \mathrm{~cm}$. Disponível: http://www.memoria.pr.gov.br/biblioteca/index.php?id_biblioteca=5. 
Por muito tempo acreditou-se ser a obra de autoria masculina, mas, de fato, teria sido pintado por Jessica James, conforme atribuição recebida. Ou Willie James, sua filha, a teria ajudado pintar o retrato? O que surpreende, é a escassez de obras deixadas pelas precursoras do ensino de artes no Paraná.

Foi no Colégio Particular Feminino James que estudaram Iria Cândida Correia, considerada a primeira pintora paranaense, e também a poetisa Júlia Maria da Costa, pois eram contemporâneas. Iria iniciou sua vida artística utilizando várias técnicas de pintura: crayon (lápis de cera de várias cores), depois pastel (giz a seco ou oleoso), aquarela e tinta a óleo, para pintar temas de ícones sacros, imagens de santos, legendas bíblicas, paisagens, naturezas-mortas e miniaturas. $\mathrm{O}$ destaque especial fica por conta dos vários retratos que Iria pintou da mãe, do pai, de outros familiares, bem como de homens e mulheres da elite, uma vez que sua família era de posses e fazia parte do círculo político e artístico da capital.

No acervo online do Museu Paranaense ${ }^{23}$ há uma dezena de pinturas da artista que podem ser acessados, todavia, é um número pequeno diante do que ela teria produzido ao longo de sua vida artística. Uma das dificuldades na atribuição de autoria das obras está justamente na ausência de assinatura, pois nem sempre assinavam suas produções. A maior parte de suas obras não chegou aos dias atuais, mas pode ser que algumas estejam em acervos particulares, e que possivelmente desconheçam a autoria, uma vez que as obras eram encomendadas ou recebidas de presente por familiares e pessoas conhecidas.

Iria Cândida Correia é considerada a primeira mulher pintora da arte paranaense:

Nasceu em Paranaguá, em 20 de outubro de 1839. Faleceu na mesma cidade em 14 de março de 1887. Iria Correia, filha do Cel. Joaquim Cândido Correia e de D. Damiana Vieira do Nascimento, família de posses, teve assim como seus nove irmãos, uma educação aprimorada

\footnotetext{
23 Museu Paranaense - Acervo online - Disponível em: http://www.museuparanaense.pr.gov.br/. Acesso em: 03 de outubro de 2015.
} 
para a época. Quando as professoras norte-americanas Jessica James e sua filha Willie, se estabeleceram em Paranaguá, em 1849, com o Colégio de Meninas, Iria Correia foi uma das jovens que a ele logo acorreram. Sua vocação para as artes revelou-se desde cedo. Apesar do ambiente cultural acanhado em que vivia e dos limitados conhecimentos pictóricos que a professora Jessica James possuía (alguns afirmam ter sido razoável desenhista e pintora), dela procurou extrair o máximo de ensinamentos. Mais tarde, aperfeiçoou-se com a Sra. Zoé Toulois - esposa do engenheiro Paulo Toulois - que fundou o Colégio Paranaense, em 1856. Na obra de Iria Correia encontram-se retratos, naturezas mortas, paisagens e composições. Seu primeiro trabalho assinado data de 1857. Em 1866, participou da Exposição Provincial do Paraná, realizada em Curitiba, com mais de uma dezena de obras em diferentes técnicas: óleo, aquarela, pastel, sépia e crayon. Iria Correia, contava nessa época 27 anos. O número de obras expostas faz supor grande produtividade. Tendo pintado até sua morte, aos 48 anos de idade, é estranhável que tão poucas obras tenham chegado até nossos dias ${ }^{24}$.

Algumas obras atribuídas à pintora Iria Correia, e que estão catalogadas no acervo online do Museu Paranaense são: a) Retrato de Manuel F. Correia Jr. - óleo sobre cartão; b) Natureza morta desenho - obra assinada pela artista - coleção David Carneiro; c) Retrato da mãe da artista - coleção David Carneiro; d) Retrato do pai da artista - coleção David Carneiro; e) Aquarela - coleção Milton Macedo Munhoz, entre outras pinturas. Em exposição no Museu Paranaense, podemos apreciar alguns objetos da artista: a) Paleta de Porcelana - coleção David Carneiro; b) Leque - coleção Milton Macedo Munhoz.

É importante destacar que as obras citadas são acervos particulares que foram integrados a esse espaço institucional, ou

24 BADEP, Panorama da Arte no Paraná. I - Dos precursores à escola Andersen. Curitiba, 1975 , p. 8. 
então, mediante doações dos familiares. Em relação às pinturas feitas por mulheres, e que estão nos acervos dos museus, é uma forma de reconhecimento - por esse instrumento cultural - da produção artística feminina. Todavia, é bem menor esse reconhecimento se comparado ao da produção masculina. E as outras mulheres artistas - aquelas que sua arte não está nos museus - que lugares elas ocupavam?

A capital paranaense, no fim do século XIX e começo do século XX, teve duas importantes escolas de artes, a primeira foi de Antônio Mariano de Lima, e a outra de Alfred Andersen, mais conhecido como Alfredo Andersen. Espaços responsáveis pela formação profissional de homens e mulheres, deixando cada um desses mestres em pintura um razoável discipulado.

No ano de 1884, havia chegado à província o jovem pintor português, Antônio Mariano de Lima, contratado pelo governo, para decorar o Theatro São Theodoro - que se tornou depois, o Teatro Guayra - em Curitiba, tarefa concluída em 1885. No ano seguinte, na capital, o pintor fundou a primeira escola de ensino de $\operatorname{artes}^{25}$, oferecendo aulas de pintura, escultura e desenho.

Segundo Adalice Araújo,

Assim é que, a 22 de julho de 1886, o Executivo Paranaense autoriza Mariano de Lima a inaugurar em uma das salas do Instituto Paranaense sua Aula de Desenho e Pintura, que, três anos após (graças ao Decreto Estadual no 1 de 29 de novembro de 1889) seria transformada em Escola de Artes e Indústrias ${ }^{26}$.

Autorizada pelo governo da província, a criação da "Escola de Desenho e Pintura" por Antônio Mariano de Lima, na realidade se tratava de uma sala de aula no Instituto Paranaense, onde se ensinava

25 Curitiba foi a terceira cidade no Brasil, a ter uma escola de artes. As primeiras foram: a Imperial Academia de Belas Artes (1816) no Rio de Janeiro, e a segunda, em Salvador. Cf. PROSSER, Elisabeth Seraphim. Arte em todo lugar: os caminhos do cotidiano e a história das artes visuais no Paraná. In: ANDREOLI, Cleverson V; TORRES, Patrícia, Lupion (orgs.). Complexidade: rede e conexões do ser sustentável. Curitiba, SENAR, 2014 (Coleção Agrinho).

26 ARAÚJO, Adalice. Dicionário das Artes Plásticas no Paraná, 2006, p.41. 
desenho e pintura. A partir de 1889, com sede própria, ampliação das artes oferecidas e sob a direção do pintor português, passa a ser chamada de "Escola de Belas Artes e Indústrias do Paraná", com várias salas de aulas frequentadas por crianças, mulheres e homens, de diferentes faixas etárias e de distintas condições sociais.

No campo das "belas artes" se oferecia cursos de pintura, desenho artístico, escultura, música, gravura e arquitetura; no setor das "artes industriais", estudava tipografia, desenho aplicado, mecânica, litografia, fotografia, marcenaria, funilaria, encadernação e prendas domésticas. Nota-se, nesse último quesito, questões de gênero e classe explícitas, primeiro porque as "artes industriais" estavam voltadas para a preparação profissionalizante das classes trabalhadoras, tendo em vista o desenvolvimento urbano e industrial da capital, e segundo, porque os cursos de prendas domésticas eram oferecidos às mulheres pobres, de baixa renda, ao contrário das mulheres da aristocracia que tinham acesso às "belas artes".

A partir de 1894, os cursos do setor das "artes industriais" foram ofertados no período noturno, para estimular as pessoas que trabalhavam durante $\mathrm{o}$ dia tivessem acesso ao ensino profissionalizante. Nessa escola, no começo do século XX, o médico, educador e político, Vítor Ferreira do Amaral e o pintor norueguês, Alfredo Andersen, foram professores dos cursos noturnos. Além deles, Georgina Leonard Mongruel e Agostinho Ermelino de Leão também ensinaram no estabelecimento ${ }^{27}$.

Uma das perspetivas do pintor Antônio Mariano de Lima era implementar o projeto da "Casa da Cultura" na capital, tanto que numa exposição realizada em Chicago no ano 1900, o pintor intitulou-a de "Casa da Cultura" e foi premiado pela iniciativa. Para essa exposição foi enviado um conjunto de obras, que antes de serem remetidas para Chicago, foram expostas na própria escola e dentre os quadros estavam o de Maria da Conceição Aguiar Lima, pintora, discípula e esposa de Antônio Mariano de Lima.

Devido ao não cumprimento das promessas do governo de investir na escola subvencionando-a, o estabelecimento escolar e o 
pintor enfrentaram uma grave crise econômica, o que o fez migrar para Manaus em 1901. A partir disso, em 1902, a escola ficou sob a responsabilidade de sua esposa e ex-aluna Maria da Conceição Aguiar Lima.

Com a saída de Mariano de Lima em 1902, sua esposa, Maria da Conceição Aguiar Lima, assumiu a direção da escola, que então teve sua orientação alterada para dar maior ênfase à educação de artes e ofícios para mulheres - tanto que, a partir de 1917, ganhou a denominação de "Escola Profissional Feminina". Em 1933 foi rebatizada como "Escola Profissional República Argentina", tendo funcionado até 1992 sob os auspícios da Secretaria de Estado da Educação. A partir deste ano foi rebatizada como "Centro de Artes Guido Viaro", funcionando até hoje nas dependências do Colégio Estadual do Paraná ${ }^{28}$.

A pintora Maria da Conceição Aguiar Lima é mencionada no livro "Panorama da arte no Paraná", publicado em 1975, e aparece atribuída a ela a pintura de uma natureza-morta, porém, não consta a imagem de sua obra e nem conseguimos localizar, por ora, maiores informações sobre sua produção artística, o que demonstra como a presença das mulheres na história da arte paranaense ainda é oculta, e carece de pesquisas.

Francisca Cândida Munhoz (1869-1942), pintora, também foi aluna de Antônio Mariano de Lima a partir de 1886, quando se matricula na "Escola de Desenho e Pintura". A artista consegue, de certa forma, se destacar no cenário cultural e expor ao público - pelo menos daquele que frequentava a escola - suas pinturas a crayon e a óleo, em que pintava retratos, paisagens e cenas como a "Despedida de Romeu", quadro que retratava a tão conhecida história de amor de Romeu e Julieta.

28 SANTANA, Luciana Wolff Apolloni. Escola de Belas Artes e Indústrias do Paraná: o projeto de ensino de artes e ofícios de Antônio Mariano Lima - Curitiba, 1886-1902. (Dissertação de Mestrado em Educação). Curitiba: UFPR, 2004, p.9. 
Entre os anos de 1884 a 1887, Francisca Cândida de Munhoz é mencionada por diversas vezes no jornal Dezenove de Dezembro ${ }^{29}$, por sua presença e participação na sociedade, êxito nos estudos, frequência nas aulas de pintura com o professor Antônio Mariano de Lima, pelo talento expresso nas suas pinturas e também por seu matrimônio com Carlos Cavalcanti de Albuquerque em meados de 1887.

É notável que o destaque dado à Francisca Cândida de Munhoz e outras mulheres da aristocracia se devia à condição social e política que suas famílias ocupavam na sociedade curitibana do fim do século XIX. Nascida em família rica, ela frequentou o Externato Santa Tereza que oferecia ensino primário e secundário e também o Colégio Curitibano que oferecia ensino primário, secundário e normal (magistério), curso no qual a pintora se formou. De boa formação, ela foi uma das poucas, em meados de 1880 , a se inscrever em exames preparatórios para o ensino superior, como exames de inglês, francês, aritmética e geografia, nos quais foi aprovada com êxito.

Porém, Francisca não saiu da capital para cursar o ensino superior, não era comum as moças deixarem suas famílias para estudar fora - ao contrário do que acontecia com os rapazes da elite e como na capital da província não havia cursos superiores, a pintora não vivenciou a experiência universitária, embora tivesse sido aprovada nos "exames preparatórios'.

A pintora Francisca Cândida de Munhoz casou-se em 1887 com o alferes Carlos Cavalcanti de Albuquerque, o qual foi presidente do estado entre os anos de 1912 e 1916. Segundo Negrão, Francisca era "senhora possuidora de esmerada educação artística; pintora e pianista" 30 .

O matrimônio exerceu assim, na vida de Francisca, o que a sociedade esperava das mulheres, o desempenho do papel de esposa e mãe. Enquanto os rapazes da capital se dirigiam ao Rio de Janeiro, São Paulo, Salvador e também a Portugal para estudarem geralmente Direito, Medicina, Engenharia, Humanidades -, Francisca

29 Jornal Dezenove de Dezembro, 1884 a 1887 - Acervo Biblioteca Romário MartinsMuseu Paranaense. 1926, vol. I e II.

30 NEGRÃO, Francisco. Genealogia Paranaense. Curitiba: Impressora Paranaense, 
por pertencer ao gênero feminino via sua vida se limitando à família e ao espaço doméstico.

Francisca, assim como outras pintoras, cedeu ao magistério se tornando professora, profissão naquele momento que não demandava de ensino superior. Muitas mulheres paranaenses que poderiam ter se tornado reconhecidas artistas, se ofuscaram no ensino. O talento de Francisca Cândida de Munhoz para a pintura foi abafado pelo choro das crianças, cuidado da casa e da família. Sua arte ficaria reclusa aos espaços privados, nas paredes de casas de familiares e pessoas conhecidas.

A segunda escola de pintura e desenho a ser inaugurada no Paraná foi instalada no começo do século XX e pertencia ao pintor norueguês Alfredo Andersen. Depois de viver um período em Paranaguá, Andersen se muda para Curitiba em 1903, onde em seguida abre uma escola particular, um ateliê de artes (desenho e pintura). O pintor também lecionava desenho na Escola Alemã e no Colégio Paranaense, bem como na Escola de Belas Artes e Indústria do Paraná - dirigida nessa época por Maria da Conceição Aguiar Lima - nos cursos noturnos de "artes industriais".

Como pintor e desenhista, dedicou-se, principalmente à paisagem e ao retrato. Alfredo Andersen é considerado o "pai da pintura paranaense", um dos grandes formadores das artes plásticas no Paraná, influenciando artistas que frequentaram sua escola. Dentre tantos (as), podemos destacar a pintora, desenhista e professora de arte, Maria Amélia D’Assumpção.

A artista teve uma educação esmerada, apaixonada por leituras, aprendeu diversas línguas, inclusive o alemão. O nome de Maria Amélia D'Assumpção surge na relação docente ao começar a frequentar o Conservatório de Belas $\operatorname{Artes}^{31}$ - criado e dirigido por Paulo Ildefonso D'Assumpção - a partir de 1894. Aos poucos ela foi se destacando no campo da pintura, e em 1917, torna-se a primeira mulher do Paraná a expor suas obras, individualmente, no Rio de Janeiro. Obtém calorosa acolhida por parte da crítica especializada

31 O Conservatório de Belas Artes teve sua abertura em 1894, em Curitiba, que mais tarde passa a se chamar Escola de Aprendizes e Artífices. Havia vários professores e professoras. Os cursos noturnos eram ofertados exclusivamente ao sexo masculino. Já as mulheres, só podiam frequentar os cursos no turno diurno. 
que elogiou suas naturezas-mortas, comparando às de pintores reconhecidos, como Pedro Alexandrino, especialista nesse gênero de pintura.

A comparação de sua produção artística com a de um artista masculino nos aponta, ao menos, dois aspectos: o primeiro, ao comparar suas obras com a de Pedro Alexandrino, a crítica reforça que para ser respeitada e considerada uma boa artista, sua arte precisava se assemelhar à obra de um artista homem, como se a qualidade da criação artística fosse apenas de competência deles; o segundo aspecto, é que embora tivéssemos outras mulheres artistas como Anita Malfatti, Georgina de Albuquerque, Tarsila do Amaral, Berthe Worms, que estavam se destacando na arte brasileira inclusive produzindo naturezas-mortas - às quais a obra de Maria Amélia D’Assumpção poderia ter sido comparada, a crítica escolheu compará-la a um artista homem, não reconhecendo nas outras artistas parâmetros de comparação, ou seja, não exaltando suas competências e expressões artísticas. Isso denota mais uma vez como a profissão artista para as mulheres custa a ser vista e aceita no mundo das artes.

Viúva desde muito cedo, Maria Amélia de Barros Mota, casa-se em 1920 com o advogado e jurista Pamphilo D'Assumpção ${ }^{32}$, de quem assume o sobrenome. Pamphilo era um admirador das artes, especialmente música e literatura, e viria a apoiar a carreira de Maria Amélia D'Assumpção. A relação afetiva com o jurista, que também publicava em jornais e revistas sobre questões jurídicas e temas relacionados às artes, abriu espaço para maior inserção da artista na sociedade e cultura paranaense.

Em Curitiba, Maria Amélia D'Assumpção lecionava pintura e desenho no Colégio Santa Júlia, do Professor Francisco Guimarães; na Escola Profissional Feminina ${ }^{33}$ e, também ministrava aulas

32 GRUNER, Clóvis. Um nome, muitas falas: Pamphilo de Assumpção e os discursos jurídicos na Curitiba da Belle Époque. Revista de História Regional, 14(1),76-104, verão 2009.

33 A Escola Profissional Feminina, em Curitiba, nasce com o propósito de oferecer às mulheres uma profissionalização diversa daquela ensinada na Escola Normal (preparação de meninas para o magistério, para serem professoras). A Escola Profissional Feminina no fim do século XIX e início do século XX direcionava seu ensino para as artes (desenho, pintura), economia doméstica e prendas manuais (datilografia, costura, bordados), ou seja, as artes aplicadas. O ensino estava voltado para jovens de classe desfavorecidas, que buscavam profissionalização, e era também procurada por jovens da classe média que buscavam aprendizados de economia doméstica e prendas manuais para administrar seus lares. Essa escola era oriunda da Escola de Artes de Antônio Mariano de Lima. Cf. 
particulares, além de participar ativamente do movimento artístico da cidade. Dedica-se à pintura até seu falecimento, ocorrido em 1955.

Maria Amélia D’Assumpção,

Nasceu em Joinville, Santa Catarina, em 1883. Faleceu em Curitiba, em 03 de setembro de 1955. Desde cedo Maria Amélia demonstrou tendência para a pintura. Seu pai, o cearense Bento Fernandes de Barros, advogado, escritor e jornalista, iniciou carreira no Paraná. Residiu durante breve período em Joinville, onde nasceu Maria Amélia, retornando em seguida a Curitiba. Aqui, aos 17 anos, Maria Amélia, casou-se com um primo, que faleceu logo depois. Viúva, com um filho, volta a residir com seu pai, que se transferira para o Rio de Janeiro. Com o falecimento do pai, em 1908, Maria Amélia, escolhe a pintura como meio de sobrevivência e passa a tomar lições com Alfredo Andersen. Seu desenvolvimento é rápido, e já em 1917 expõe no Rio de Janeiro, recebendo calorosa acolhida da crítica. Suas naturezas mortas são comparadas às do mestre Pedro Alexandrino. Em 1920, Maria Amélia de Barros Mota, como assinava até então, casa-se com o Dr. Pamphilo D'Assunção, conhecido jornalista e aficcionado das artes. Falecendo aos 72 anos de idade, a artista deixou vasta obra, onde a técnica apurada e a grande sensibilidade estiveram sempre presentes $^{34}$.

Um retrato da própria artista - Retrato de Maria Amélia D' Assumpção - foi pintado por seu mestre Alfredo Andersen e está disponível no acervo do Museu Paranaense. Na obra "Panorama da arte no Paraná, 35 consta uma foto de Maria Amélia D’Assumpção acompanhada de um menino, seu filho.

FREITAS, Daniele Gross de. A educação das mulheres e a proposta da Escola Profissional Feminina de Curitiba. Disponível em: www.sbhe.org.br/novo/congressos/cbhe6/anais_vi_cbhe/.../1303.doc. Acesso em: 01 de novembro de 2015.

34 BADEP, Panorama da Arte no Paraná. Curitiba, 1975, p. 8.

35 Idem, Ibidem, 1975, p.15. 
Algumas pinturas produzidas por Maria Amélia são: a) Amor-perfeito - coleção Herculano de Macedo Souza; b) Naturezamorta - coleção Simeão Pedroso; c) Natureza-morta - coleção Albano Ewaldo Wendler; d) Natureza- morta - coleção Associação Comercial do Paraná; e) Rosas - coleção Carlos Heller; f) Flores coleção Maria Francisca Meder Velloso; g) Dálias - coleção Oscar Martins Gomes. Obras de coleções particulares que foram doadas e integradas ao acervo do Museu Paranaense.

As escolas de artes plásticas de Alfredo Andersen e Antônio Mariano de Lima contribuíram para que o objetivismo visual e a tendência realista de suas expressões artísticas influenciassem as primeiras gerações da pintura paranaense.

Todavia, na capital do Paraná, até a década de 1920, o mercado artístico era muito pequeno, difícil para artistas sobreviverem das artes, tanto homens quanto mulheres. Mas certamente muito mais complicado para elas. Pois enquanto os jovens pintores, intelectuais e jornalistas se reuniam em espaços públicos, ateliês e ruas para conversarem sobre arte, culminando num movimento de arte moderna no estado - início do paranismo ou "estilo paranista" - impulsionado pela imprensa, as mulheres naquele contexto histórico não tinham tanta liberdade para isso, o que demonstra como a condição de ser mulher, naquela época, é um dos fatores que dificultaram o acesso ao mundo das artes. A elas, alguns espaços e comportamentos eram restritos, negados.

Nos primeiros anos do século XX, algumas artistas se destacaram no campo da pintura, e a grande maioria delas teve aulas na escola/ateliê de Alfredo Andersen, as quais podemos citar: Maria Amélia D’Assumpção, Isolde Hotte, Inocência Falce, Silvina Bertagnolli, uma vez que Andersen foi grande formador das primeiras gerações de pintores e pintoras do estado ${ }^{36}$.

No Dicionário das Artes Plásticas do Paraná, de Adalice de Araújo $^{37}$, encontramos referências da presença e atuação dessas mulheres pintoras, como Isolde Hötte Johann (1902-1994), nascida

36 Mulheres pintoras, discípulas de Alfredo Andersen. Ver: Museu Alfredo Andersen, disponível em: http://www.maa.pr.gov.br/modules/conteudo. Acesso em: 14 de outubro de 2015. ARAÚJO, Adalice. Op. Cit., 2006.

37 ARAÚJO, Adalice. Op. Cit., 2006. 
em Curitiba, filha de imigrantes alemães, foi aluna de Alfredo Andersen durante sua adolescência e depois dessa fase de estudo com o pintor, a artista morou dois anos na Alemanha onde aperfeiçoou suas técnicas. De retorno ao Brasil foi aluna de Lange de Morretes e também da ceramista e professora Adelaide Knauer, encontrando na cerâmica novas formas de se expressar. A artista teve uma extensiva produção.

Inocência Falce (1899-1984), nasceu em Curitiba e estudou pintura entre os anos de 1930 e 1935 com Alfredo Andersen. A produção da artista representava flores e motivos da natureza, e devido a um incêndio que teria destruído grande parte de suas obras, ficou difícil alcançar reconhecimento do público. A artista também se dedicou ao ensino das artes.

Também nascida em Curitiba, a artista Silvina Bertagnoli (1912-1975), após a conclusão do curso normal (magistério) ingressou na Escola de Alfredo Andersen, de quem também foi discípula, se especializando na pintura de naturezas-mortas e paisagens paranaenses ${ }^{38}$. Teve participação em várias exposições coletivas, e no ano de 1944 participou do I Salão Paranaense de Belas Artes. A artista também havia estudado música na Academia de Música do Paraná e foi professora de piano.

Além delas, temos que destacar ainda, Sinhazinha Rebello (1891-1973), nasceu em Curitiba e estudou pintura com Alfredo Andersen, entre os anos de 1930 e 1935. A artista pintava tachos, louças, cristais e flores com muito realismo. Na maioria das vezes distribuía suas obras para as pessoas amigas, raramente as vendia. Teve grande produção artística, embora não as expusesse com frequência.

Nascida em Palmeira, Lydia de Marco (1914-1993), ainda na sua infância foi aluna de Alfredo Andersen, o que demonstra o grande discipulado que o artista teve, tanto de mulheres quanto de homens artistas. A artista pintava retratos e trabalhava como colorista para fotógrafos.

Maria Sylvia Senff Palú, nascida em 1917 em Curitiba, foi aluna de Lange de Morretes, e também de Alfredo Andersen e 
Inocência Falce, o que mostra a inserção das primeiras alunas de Andersen no ensino das artes. Se por um lado, isso demonstra os conhecimentos e habilidades técnicas adquiridas, por outro revela como o campo da educação e a profissão de professora de artes se tornou a única oportunidade de muitas das prováveis promissoras artistas, ofuscando a profissionalização e talento artístico. Anos mais tarde, Palú daria aulas na Escola Profissional República Argentina, onde havia estudado e seria colega de trabalho de Maria Amélia D'Assumpção.

Ainda no campo da pintura, é importante lembrarmo-nos de Gene Woiski, que além de pintora, era decoradora. Nascida nos Estados Unidos, a artista radicou-se no Paraná e foi casada com o pintor e escultor João Woiski. A artista especializou-se como retratista, bem como na pintura em móveis, sobretudo com temas orientais, chegando a participar juntamente com vários (as) artistas da primeira exposição itinerante de arte do Paraná, em 1948, promovida pelo Departamento de Cultura e Divulgação da Secretaria de Educação, realizada nos salões da sede social do "Club Litterario", uma grandiosa exposição de pintura e desenho. A artista permaneceu no Paraná até 1950.

Apesar das dificuldades encontradas, a inserção e presença das mulheres artistas revela o protagonismo feminino no campo da arte, da cultura e do ensino no Paraná, na transição do século XIX para o século XX.

\section{Considerações finais}

Abordar o contexto artístico paranaense, de fins do século XIX e começo do século XX, no que se refere à relação entre arte $\mathrm{e}$ gênero nos aponta que a realidade de inserção das mulheres nas artes e na profissão de artista não foi muito diferente do que acontecia nacional e internacionalmente. As mulheres artistas vivenciaram um processo de marginalidade da história, do processo criativo, dos 
espaços públicos, lugares e posições sociais delimitadas por códigos de uma sociedade patriarcal.

As desigualdades de gênero impostas e apregoadas pelo patriarcalismo é um dos fatores responsáveis, até pouco tempo atrás, por grande parte das mulheres não terem acesso à alfabetização e aos espaços das artes; e as que tiveram acesso, sobraram poucos registros, o que faz com que sejam menos reconhecidas. Isso revela como a arte produzida por mulheres, nas suas mais diversas expressões, e também a profissão de artista, enfrentou diversas dificuldades para serem aceitas e valorizadas num ambiente cultural e artístico predominantemente ocupado por homens.

Sabemos que até a contemporaneidade os registros da produção artística de mulheres são relativamente menores em comparação aos de homens artistas. Isto se dá devido a vários fatores predominantes na cultura brasileira e paranaense que atribuem papéis diferenciados de gênero, e que por muito tempo direcionou as mulheres ao papel de donas de casa, mães, impedindo-as de estudar, se profissionalizar e alcançar uma carreira, acarretando assim, dificuldades para a inclusão no mercado de trabalho, e igualmente no mundo das artes, o que é muito recente.

Com este trabalho constatamos que paulatinamente as mulheres foram se inserindo no mundo das artes no cenário paranaense. No fim do século XIX sua presença aconteceu com bastante modéstia, devido às limitações sociais impostas a elas, que as impediam de ocupar vários lugares, especialmente os espaços públicos. Já nas primeiras décadas do século XX, impulsionadas pelo modernismo e pelas lutas femininas por emancipação, as artistas alcançaram maior destaque e conseguiram se expressar ocupando lugares antes não permitidos, se inserindo e se manifestando no campo das artes, que embora pintoras, literatas, musicistas, poetisas, atrizes de teatro, escultoras, encontrassem dificuldades para alcançar espaço na sociedade - assim como nas demais profissões - elas existiam e cada vez se proliferavam mais, participando do processo criativo, da produção e composição do mundo, rompendo com estereótipos e marcações de gênero.

RECEBIDO EM: 11/05/2016

APROVADO EM: 22/05/2017 